\title{
Kamu Binalarında Mevcut Aydınlatma Elemanlarının LED Aydınlatma Elemanlarına Dönüştürülmesi ile Elde Edilecek Elektrik Enerjisi Tasarrufunun Belirlenmesi
}

\author{
Sema Y1maz ${ }^{1 *}$, Cemil Sungur ${ }^{2}$ \\ ${ }^{1}$ Selçuk Üniversitesi, Bozkır Meslek Yüksekokulu, Elektrik ve Enerji Bölümü, Konya, Türkiye (ORCID: 0000-0000-0000-0000) \\ ${ }^{2}$ Konya Teknik Üniversitesi, Mühendislik ve Doğa Bilimleri Fakültesi, Elektrik-Elektronik Bölümü, Konya, Türkiye (ORCID: 0000-0000-0000-0000)
}

( $1^{\text {st }}$ International Conference on Computer, Electrical and Electronic Sciences ICCEES 2020 - 8-10 Ekim 2020)

(DOI: $10.31590 /$ ejosat.804256)

ATIF/REFERENCE: Yılmaz, S. \& Sungur, C. (2020). Kamu Binalarında Mevcut Aydınlatma Elemanlarının LED Aydınlatma Elemanlarına Dönüştürülmesi ile Elde Edilecek Elektrik Enerjisi Tasarrufunun Belirlenmesi. Avrupa Bilim ve Teknoloji Dergisi, (Özel Say1), 214-218.

Öz

Her zaman önem arz eden elektrik enerjisi ihtiyacını karşılamak kadar onu tasarruflu kullanmak olukça önemlidir. Bunun için Kamu binalarında kullanılan aydınlatma elemanlarının tükettiği elektrik enerjisinin ne kadar verimli olduğu konusunda bir incelemeye ihtiyaç duyulmuştur.

Bu çalışmanın amacı günümüzde floresan lambalar ve tasarruflu ampullerin alternatifi olarak kullanılmaya başlanan ve düşük güç harcayan LED (Light Emitting Diode, Işık Yayan Diyot) aydınlatma ürünlerinin kullanılmasıyla elektrik enerjisi tasarrufu elde edilebileceğini belirlemektir.

Bunun için okullarda hâlihazırda kullanılmakta olan aydınlatma elemanlarının, LED aydınlatma elemanlarına dönüştürülmesi ile oluşacak enerji tasarrufu hesaplanacaktır. Böylece aydınlatma elemanlarının değiştirilmesiyle önemli miktarda elektrik enerjisi tasarrufu sağlanabileceğinin kanıtlanması amaçlanmaktadır.

Kamu binalarında Elektrik enerjisi tasarrufunun arttırılmasına katkıda bulunmayı amaçlayan çalışmanın sonucunda pilot olarak belirlediğimiz kamu binasındaki gücü 40 watt olan aydınlatma elemanlarını, 24 watt led aydınlatma elemanları ile değiştirerek elektrik enerjisi tüketiminden yıllık \%40 oranında tasarruf edileceği belirlenmiştir.

Anahtar Kelimeler: Elektrik Enerjisi Tasarrufu, LED Lamba, Enerji Verimliliği, İç Aydınlatma, Kamu Binalarında Enerji Tasarrufu

\section{Determination of Electrical Energy Savings When Existing Lighting Elements in Public Buildings are Transformed into LED Lighting Elements}

\begin{abstract}
It is very important to use it economically as well as meeting the electrical energy need, which is always important. For this, it was necessary to examine how efficient the electrical energy consumed by the lighting elements used in public buildings is.

The aim of this study is to determine that electrical energy savings can be achieved by using LED (Light Emitting Diode) lighting products, which are used today as an alternative to fluorescent lamps and energy-saving lamps and consume low power.

For this, energy savings will be calculated by transforming the lighting elements currently used in schools into LED lighting elements. Thus, it is aimed to prove that a significant amount of electrical energy can be saved by changing the lighting elements.

As a result of the study aimed at contributing to the increase of electrical energy savings in public buildings, it was determined that 40 percent savings would be achieved when lighting elements in the pilot public building with a power of 40 watts were replaced with 24 watt led.
\end{abstract}

Keywords: Electric Energy Saving, LED Lamp, Energy Efficiency, Energy Savings in Public Buildings.

\footnotetext{
*Sorumlu Yazar: Sema Yılmaz, Selçuk Üniversitesi, Bozkır Meslek Yüksekokulu, Elektrik ve Enerji Bölümü Bozkır/Konya, ORCID: 0000-00000000-0000, semayilmaz@selcuk.edu.tr
} 


\section{Giriş}

Enerji tasarrufunun ülke ekonomisine sağlayacağı olumlu katkılar büyük boyutlara ulaşabilmektedir. Tasarruf edilen enerji, en kolay elde edilen enerjidir. Aydınlatmada enerji tasarrufu, aydınlatmanın kalitesini düşürmeden ve iyi bir aydınlatmanın şartları yerine getirilerek yapılmalıdır. İyi bir aydınlatma, daha verimli aydınlatma elemanları ile sağlanacağı için, aynı aydınlatma seviyesinin daha az enerji tüketimi ile sağlanması mümkündür (Perdahçı ve Hanlı, 2010).

Aydınlatmada yapılacak iyileştirmeler, bina işletme maliyetlerini \%10 azaltarak, \%30'dan fazla enerji tasarrufu sağlayabilir (Özdeniz, 2018).

Kamu binalarında aydınlatma sistemlerinde enerji tasarrufu, aydınlatmanın kalitesini düşürmeden ve iyi bir aydınlatmanın kuralları yerine getirilerek yapılmalıdır (Gökmen, 2006). Kaliteli aydınlatma, daha verimli aydınlatma elemanları ile sağlanacağı için, aynı aydınlatma seviyesinin daha az enerji tüketimi ile sağlanması mümkündür (Örücü, 2017). Verimli bir aydınlatma ile daha çok elektrik enerjisi tasarrufu sağlanacaktır (Meral, Ahmet ve Tümay, 2009).

$\mathrm{Bu}$ nedenlerle günümüzde mevcut aydınlatma elemanlarına alternatif olarak \%85 enerji tasarrufu sağlayan, LED lambaları kullanmaya başlamak zorunlu hale gelmiştir (Yenilenebilir Enerji, 2017).

$\mathrm{Bu}$ çalışmada; aydınlatmada yapılacak enerji tasarrufunun sağlayacağı yararlar, doğru ve verimli bir aydınlatma için yapılması gerekenler ve aydınlatmada enerji tasarrufu yapılırken dikkat edilmesi gereken hususlar belirlenecektir.

\section{Materyal ve Metot}

Bu çalışmada pilot kamu binası olarak Konya ili Bozkır İlçesi Milli Eğitim Müdürlüğü’ne bağlı 16 derslikli Derviş Mustafa Öztunç İlköğretim Okulu seçilmiştir. Çalışmanın başlangıcında İlk olarak okuldaki aydınlatma amacı için kullanılan lambaların günlük, aylık ve yıllık kullanım süreleri, hesaplanarak ve güçleri tespit edilmiştir. Alınan bu değerlerden hareketle örnek okulun aydınlatma sisteminin yıllık elektrik enerjisi tüketim miktarı hesaplanmıştır.

Bu okulda bulunan sınıf, laboratuvar, öğretmenler odası, kütüphane, vs. olarak kullanılan birimlerin aydınlık düzeyleri ölçülmüş, çıkan sonuçların, Elektrik Mühendisleri Odası tarafından yayımlanan En Az Aydınlık Düzeyleri Tablosunda verilen standartlara uygun olup olmadı̆̆ karşılaştırılmıştır.

İkinci adımda mevcut aydınlatma elemanlarının LED lambalarla değiştirilmesi sağlanarak aynı birimler için aydınlık şiddeti ölçümler tekrarlanmıştır.

Elde edilen sonuçların karşılaştırılması ile bir yıl içerisinde pilot okulda aydınlatma sisteminin harcadığı elektrik enerjisinden elde edilecek tasarruf miktarı hesaplanmıştır. (Bozkır Kaymakamlı̆̆ı, 2018).

\section{Araştırma Sonuçları ve Tartışma}

\subsection{Okul Ortam Aydınlık Düzeylerinin Durumu}

Okuldaki ortamların aydınlık düzeyleri ölçüm sonuçları Tablo 1'de yer almaktadır. Yönetmeliğe göre sınıfların aydınlık şiddetleri 300 lüx laboratuvarların 500 lüx olması gerektiği bilinmektedir (EMO, 2017). Buna rağmen başta sınıflar olmak üzere ortamların aydınlatma şiddetleri lambalar ister açık ister kapalı olsun yönetmelikte belirtilen değerlerden oldukça düşük düzeydedir (Tablo 1). 
Avrupa Bilim ve Teknoloji Dergisi

Tablo 1. Okuldaki Ortamların Aydınlık Düzeyleri

\begin{tabular}{|c|c|c|}
\hline \multirow{2}{*}{ Ortam } & \multicolumn{2}{|c|}{40 Watt Floresan Lamba Aydınlık Düzeyi- (LÜX) } \\
\hline & Lambalar KAPALI & Lambalar AÇIK \\
\hline 1-A Sinifi & 49 & 147 \\
\hline 1-B Sinıfi & 45 & 145 \\
\hline 1-C Sinifi & 34 & 157 \\
\hline 2-A Sinıfi & 50 & 150 \\
\hline 2-B Sinıfi & 45 & 144 \\
\hline 2-C Sinıfi & 60 & 154 \\
\hline Ana Sinifi 1 & 160 & 184 \\
\hline Özel Eğitim Sınıf 1 & 141 & 175 \\
\hline 3-A Sinifi & 84 & 127 \\
\hline 3-B Sinıfi & 80 & 130 \\
\hline 3-C Sinıfi & 75 & 140 \\
\hline 4-A Sinifi & 132 & 169 \\
\hline 4-B Sinıfi & 28 & 45 \\
\hline 4-C Sinıfi & 55 & 90 \\
\hline Ana Sinıfi 2 & 155 & 190 \\
\hline Özel Eğitim Sınıfı 2 & 130 & 160 \\
\hline Bodrum Koridor & 3 & 50 \\
\hline Birinci Kat Koridor & 7 & 44 \\
\hline Zemin Kat Koridor & 2 & 41 \\
\hline Fen Laboratuvarı & 56 & 0 \\
\hline Kütüphane & 60 & 205 \\
\hline Öğretmenler Odas1 & 86 & 150 \\
\hline Müdür Odas1 & 108 & 216 \\
\hline Müdür Yardımcısı & 90 & 140 \\
\hline
\end{tabular}

\subsection{Okuldaki Mevcut Aydınlatma Elamanlarının Elektrik Enerjisi Tüketimi}

Okulda bulunan ortamların, dolayısı ile aydınlatma elemanlarının kullanım süreleri farklıdır. Şöyle ki, Millî Eğitim Bakanlığına bağlı okullarda bir yılda toplam 180 iş günü eğitim öğretim yapılmaktadır. Okuldaki ortamların kullanım süreleri farklı olduğu için hesaplamalarda, aydınlatma elemanlarının kullanım süreleri ortalama değerler alınmıştır. Buna göre lamba kullanım süreleri bir yılda, 180 iş günü günlük 2 ila 8 saat alınırken, bazılarının kullanım süreleri bir yılda 90 iş günü yarım saat ila 6 saat arasında alınmıştır. Tüm bunlar dikkate alınarak okulda bulunan 246 adet 40 watt floresan lambanın yıllık elektrik enerjisi tüketimi 6474,04kwh olarak hesaplanmıştır. 
Tablo 2. Okulda Lamba Tasarruf Edilmesi Planlanan Elektrik Enerjisi Miktarl

\begin{tabular}{|c|c|c|c|c|c|c|c|c|c|c|c|c|}
\hline Ortam & \begin{tabular}{|c|} 
Bodrum \\
Kat \\
Lamba \\
Adedi
\end{tabular} & $\begin{array}{c}\text { Zemin } \\
\text { Kat } \\
\text { Lamba } \\
\text { Adedi }\end{array}$ & $\begin{array}{c}\text { Normal } \\
\text { Kat } \\
\text { Lamba } \\
\text { Adedi }\end{array}$ & \begin{tabular}{|c|} 
Günlük \\
Kullanım \\
Süresi - \\
Saat
\end{tabular} & $\begin{array}{c}\text { Yıllık } \\
\text { Kullanım } \\
\text { Süresi - } \\
\text { Gün }\end{array}$ & $\begin{array}{c}40 \text { Watt } \\
\text { Floresan } \\
\text { Lamba ile } \\
\text { Yıllık } \\
\text { Elektrik } \\
\text { Enerjisi } \\
\text { Tüketimi } \\
\text { - kwh }\end{array}$ & \begin{tabular}{|c|}
24 Watt \\
LED \\
Lamba ile \\
Yıllık \\
Elektrik \\
Enerjisi \\
Tüketimi \\
- kwh \\
\end{tabular} & \begin{tabular}{|c|} 
Floresan Lamba \\
ile 24 Watt LED \\
Lamba \\
Kullanımı \\
Arasındaki \\
Fark, Yıllık \\
Elektrik \\
Enerjisi \\
Tasarufu - kwh \\
\end{tabular} & \begin{tabular}{|c}
24 Watt LED \\
Ampul \\
Bağlanması \\
ile Bir Yllık \\
Elektrik \\
Enerjisi \\
Tasarrufu \\
\end{tabular} & \begin{tabular}{|c}
10 Watt \\
LED \\
Lamba ile \\
Yıllık \\
Elektrik \\
Enerjisi \\
Tüketimi \\
- kwh
\end{tabular} & \begin{tabular}{|c|} 
Floresan Lamba \\
ile 10 Watt LED \\
Lamba \\
Kullanımı \\
Arasındaki \\
Fark, Yıllık \\
Elektrik \\
Enerjisi \\
Tasarufu - kwh \\
\end{tabular} & $\begin{array}{c}10 \text { Watt LED } \\
\text { Ampul } \\
\text { Bağlanması } \\
\text { ile Bir Yıllık } \\
\text { Elektrik } \\
\text { Enerjisi } \\
\text { Tasarrufu } \\
\end{array}$ \\
\hline Koridor 1 & 8 & & & 4 & 180 & 230,4 & 138,24 & 92,16 & $\% 40$ & 57,6 & 172,8 & $\% 75$ \\
\hline Koridor 2 & & 16 & & 8 & 180 & 921,6 & 552,96 & 368,64 & $\% 40$ & 230,4 & 691,2 & $\% 75$ \\
\hline Koridor 3 & & & 24 & 8 & 180 & 1382,4 & 829,44 & 552,96 & $\% 40$ & 345,6 & 1036,8 & $\% 75$ \\
\hline Fen Lab. & 8 & & & 2 & 180 & 115,2 & 69,12 & 46,08 & $\% 40$ & 28,8 & 86,4 & $\% 75$ \\
\hline Yemekhane & 12 & & & 2 & 180 & 172,8 & 103,68 & 69,12 & $\% 40$ & 43,2 & 129,6 & $\% 75$ \\
\hline Bulaşıkhane & 1 & & & 2 & 180 & 14,4 & 8,64 & 5,76 & $\% 40$ & 3,6 & 10,8 & $\% 75$ \\
\hline Top. Salonu & 16 & & & 4 & 4 & 10,24 & 6,144 & 4,096 & $\% 40$ & 2,56 & 7,68 & $\% 75$ \\
\hline Arşiv & 1 & & & 0,5 & 90 & 1,8 & 1,08 & 0,72 & $\% 40$ & 0,45 & 1,35 & $\% 75$ \\
\hline Depo (3 adet) & 8 & & & 0,5 & 90 & 14,4 & 8,64 & 5,76 & $\% 40$ & 3,6 & 10,8 & $\% 75$ \\
\hline $\begin{array}{l}\text { Normal Sinıf } \\
\text { (14 adet) }\end{array}$ & & 64 & 64 & 6 & 90 & 2764,8 & 1658,88 & 1105,92 & $\% 40$ & 691,2 & 2073,6 & $\% 75$ \\
\hline Ana Sinıfi & & 2 & & 8 & 180 & 115,2 & 69,12 & 46,08 & $\% 40$ & 28,8 & 86,4 & $\% 75$ \\
\hline $\begin{array}{l}\text { Özel Eğitim } \\
\text { Sinıfi (2 adet) }\end{array}$ & & 4 & & 8 & 180 & 230,4 & 138,24 & 92,16 & $\% 40$ & 57,6 & 172,8 & $\% 75$ \\
\hline Müdür Odası & & & 2 & 1 & 90 & 7,2 & 4,32 & 2,88 & $\% 40$ & 1,8 & 5,4 & $\% 75$ \\
\hline Müdür Yard. & & & 2 & 1 & 90 & 7,2 & 4,32 & 2,88 & $\% 40$ & 1,8 & 5,4 & $\% 75$ \\
\hline Öğret. Odası & & & 8 & 8 & 180 & 460,8 & 276,48 & 184,32 & $\% 40$ & 115,2 & 345,6 & $\% 75$ \\
\hline $\begin{array}{l}\text { Güvenlik } \\
\text { Odası }\end{array}$ & & 1 & & 1 & 90 & 3,6 & 2,16 & 1,44 & $\% 40$ & 0,9 & 2,7 & $\% 75$ \\
\hline $\begin{array}{l}\text { Hizmetli } \\
\text { Odası }\end{array}$ & & 1 & & 1 & 90 & 3,6 & 2,16 & 1,44 & $\% 40$ & 0,9 & 2,7 & $\% 75$ \\
\hline Kütüphane & & & 2 & 2 & 90 & 14,4 & 8,64 & 5,76 & $\% 40$ & 3,6 & 10,8 & $\% 75$ \\
\hline Mescid & & & 2 & 0,5 & 90 & 3,6 & 2,16 & 1,44 & $\% 40$ & 0,9 & 2,7 & $\% 75$ \\
\hline TOPLAM & & & & & & 6474,04 & 3884,424 & 2589,616 & $\% 40$ & 1618,5 & 4855,53 & $\% 75$ \\
\hline
\end{tabular}

Okuldaki 40 watt floresan lambalar 24 watt LED lambalarla değiştirildiği takdirde bir yılda 2589,616 kwh elektrik enerjisi tasarrufu elde edilecektir. Bu da aydınlatma sisteminden yaklaşık olarak bir yılda \% 40 oranında elektrik enerjisi tasarrufu sağlanacak demektir.

Aynı şartlar altında floresan lambalar eğer 10 watt LED ampullerle değiştirilirse aydınlatma sisteminin yıllık elektrik enerjisi tüketimi 4855,53 kwh olacaktır. Bu da aydınlatma sisteminden bir yılda \%75 oranında elektrik enerjisi tasarrufu sağlanacak demektir. Tablo 2'de ayrıntılar yer almaktadır.

Buna göre LED lamba teknolojisi, floresan lambalarla kıyaslandığı zaman; aydınlık şiddeti yüksek, harcadığı güç az ve şebekeden çektiği akım daha az olduğundan elektrik enerjisi tasarrufu yapılması için en uygun lamba çeşididir (Floresanın Zararları, 2017).

Aydınlatma elemanlarının değişimi ilk başta okula ya da kuruma bir maliyet getirecektir. Ancak bu maliyet elektrik enerjisinden elde edilecek kar ile kısa sürede karşılanacaktır (Resmî Gazete, 2007).

\section{Sonuç}

Bu uygulama çalışması örnek alınarak Türkiye genelinde, kamu binalarında aydınlatma elemanlarının değiştirilmesi halinde büyük miktarlarda elektrik enerjisinden tasarruf edileceği tahmin edilmektedir.

Ülkemizde elektrik enerjisini verimli kullanmak son derece önem arz etmektedir. Şöyle ki; TEİAŞ tarafindan paylaşılan elektrik enerjisi üretiminde yerlilik bilgileri Tablo 3'te yer almaktadır. Bu tabloya göre, 16.08.2017 Çarşamba günü 945.000 .048 kwh elektrik enerjisi üretimi gerçekleştirilmiştir (TEİAŞ, 2019). Bunun \%41,24'ü yerli kaynaklardan, \%58,76’sı ise ithal kaynaklardan karşılandı̆̆ tablodan anlaşılmaktadır.

Tablodan da görüldüğü gibi bu çalışma acilen uygulamaya konulması gereken bir çalışmadır. 
Avrupa Bilim ve Teknoloji Dergisi

Tablo 3. 16.08.2017 Tarih İtibari ile Elektrik Enerjisi Üretiminde Yerlilik Oranı

\begin{tabular}{|l|c|c|}
\hline \multicolumn{3}{|c|}{ 16.08.2017 Elektrik Enerjisi Üretiminde Yerlilik Oranı } \\
\hline Yerli kaynaktan üretim & $389.718 .188 \mathrm{kwh}$ & $\% 41,24$ \\
\hline İthal kaynaktan üretim & $555.281 .860 \mathrm{kwh}$ & $\% 58,76$ \\
\hline
\end{tabular}

Tüm bunlar dikkate alındığı zaman daha az güç harcayan, daha az akım çeken ve de aydınlık şiddeti floresan lambalardan daha yüksek olan LED lamba aydınlatması, elektrik enerjisi tasarruf etme elemanlarından biri olacaktır.

Özellikle ve öncelikle okullarda sonra da kamu binalarında ivedi olarak LED lamba kullanımının yaygınlaştııılması bunun için de sorumluların bilinçlendirilmesi hatta bu konularda eğitimler verilmesi gerekmektedir.

Yapılan deneysel çalışmaların sonucunda pilot olarak seçilen kamu binasında mevcut akkor flemanlı ve floresan lambaların LED ampullerle değiştirilmesi sonucunda yaklaşı \% $\% 0$ oranında tasarruf edilebileceği belirlenmiştir. Bu değer enerji konusunda dışa bağlı olan ülkemiz için oldukça önemlidir.

\section{Teşekkür}

Bu makale 18401006 no.lu BAP projesinden yayımlanmıştır. Bu çalışmaya, desteklerinden dolayı Bozkır Kaymakamı'na, Bozkır İlçe Milli Eğitim Müdürü’ne teşekkür ederim.

\section{Kaynakça}

Özdeniz, D. Ofislerde Aydınlatma Otomasyonu, (05.12.2018), http://www.emo.org.tr/ekler/0d965fca19f20cc_ek.pdf

Meral, M. E., Ahmet, T., ve Tümay, M. (2009). Elektrik tesislerinde enerji verimliliği. Uludağ University Journal of The Faculty of Engineering, 14(1).

Örücü, O. (16.08.2017). LED ampullere doğru. http://www.emo.org.tr/ekler/c132bf75f698eed_ek.pdf?dergi=905

Enerji verimliliği. (16.08.2017). https://yenilenebilirenerjiproje.wordpress.com/author/globalproje/page/2/

Yük Tevzi Bilgi Sistemi. (06.01.2019). https://ytbs.teias.gov.tr/ytbs/frm_login.jsf

Elektrik Mühendisleri Odası. (16.08.2017). http://www.emo.org.tr/ekler/c132bf75f698eed_ek.pdf?dergi=905

Gökmen, M. (2006). Sihirli Formül Tasarruf. (10.01.2019) http://www.yeniasya.com.tr/2006/12/20/dizi/default.htm

Bozkır Kaymakamlığı. (2018). Bilgi İhtiyacı, Sayı: 19923680-492-E.274.

Perdahçı, C. ve Hanlı, U., "Verimli Aydınlatma Yöntemleri” 3E Electrotech, Mart 2010.

Floresanın Zararları, (20.07.2017) https://www.ledayled.com/beni-oku-floresanin-zararlari/

Resmî Gazete. (2007). Tasarruf Tedbirleri Genelgesi. (20.09.2018) http://www.resmigazete.gov.tr/eskiler/2007/01/20070118-13.htm 